\title{
ANTOLOGIA: ESCRITA COMPILADA, \\ DISCURSO E CAPITAL SIMBÓLICO
}

Silvana Serrani

- (BENEDICT, Barbara. Making the modern reader: Cultural Mediation in Early Modern Literary Anthologies. Princeton, NJ: Princeton University Press, 1996: 3.)

\section{Introdução}

A antologia é um gênero discursivo que oferece muita informação sobre o modo em que se escreve e lê literatura e sobre seu papel em uma cultura e época dadas e, como se sabe, o gênero contribui diretamente para formar e transformar cânones, confirmar reputações literárias e estabelecer ou interferir em práticas letradas de gerações de leitores. ${ }^{*}$ Contudo, as antologias não têm recebido suficiente atenção crítica ou analítica específica. Abordagens baseadas na Análise do Discurso ${ }^{1}$ trazem contribuições, que procuraremos pôr em evidência neste artigo, ilustrado principalmente com exemplos dos Estudos Hispânicos, mas com referências, também, a outros contextos. As funções da antologia na construção do leitor, na representação político-cultural de literaturas nacionais ou regionais e suas funções na educação são tópicos cruciais, que são tratados na primeira parte, para a compreensão do funcionamento do gênero. Na segunda parte, apresentam-se resultados de um estudo de caso sobre antologias bilíngües de poesia argentina e se discute a relevância do gênero em relação à noção de transnacionalidade cultural.

\section{Discurso e materialidade do gênero Antologia}

\section{Antologia/Coletânea e gênero discursivo}

A reflexão sobre duas realizações materiais do gênero, a coletânea e a antologia (no sentido etimológico do termo de seleção, "buquê das melhores flores"), é relevante para enfocar as antologias enquanto discurso. A distinção se torna mais evidente na épo-

${ }^{1}$ Esse enfoque é predominante nas investigaçōes sobre antologias de diversos gêneros, realizadas pelo grupo de pesquisa Antologias, Discurso e Práticas Letradas (www.antologiasediscurso.iel.unicamp.br), que coordeno no IEL-UNICAMP, com apoio do CNPq e da FAPESP. Fica aqui registrado meu agradecimento a essas agências de fomento à pesquisa. Agradeço muito também a leitura crítica deste texto realizada por Walter C. Costa (UFSC). 
ca de consolidação do gênero, no século XVIII na Inglaterra, com a presença de dois fatores, inexistentes no Renascimento e escassos no século XVII: volume crescente de literatura impressa e aumento do público letrado. Como expõe Benedict, no começo do século XVIII predominavam as coletâneas, organizadas por livreiros e com a característica saliente de apostar nas novidades, enquanto, no final do século, são típicas as antologias literárias, compilações que seguem um levantamento histórico, realizado por editores e homens de letras prestigiosos. Essa distinção coletânea/antologia levou a algumas conclusões generalizantes, que é preciso reconsiderar. Por exemplo, no âmbito dos Estudos Hispânicos, a antologista e estudiosa do gênero, Barbara Mujica, apoiando-se em Benedict, conclui: "[...] enquanto uma coletânea convida a leituras breves e desconexas, uma antologia convida a estudo prolongado. As antologias comportam a noção de evolução (a sucessão de movimentos literários) e de hierarquia (o reconhecimento de obras de arte)..$^{2^{*}}$

Entretanto, a concepção bakhtiniana de gênero discursivo nos leva a concluir que a caracterização discursiva de uma compilação não pode ser estabelecida a priori:

[...] todas as esferas da atividade humana, por mais variadas que sejam, estão sempre relacionadas com a utilização da língua [...] [e] cada esfera de utilização da língua elabora seus tipos relativamente estáveis de enunciados, sendo isso que denominamos gêneros do discurso [...]. Não há razão para minimizar a extrema heterogeneidade dos gêneros do discurso e a conseqüente dificuldade quando se trata de definir o caráter genérico do enunciado.

Somente após uma análise do processo de circulação, dos efeitos de memória mobilizados na antologia, suas fontes primárias os textos selecionados na compilação - e suas fontes secundárias os prólogos, prefácios, estudos preliminares, posfácios, bio-bibliografias de autores ou tradutores e notas, etc. -, pode-se explicar por que há coletâneas que se tornam "antológicas", no sentido etimológico do termo, e seleçóes que, apresentadas como supostamente "essenciais", não são reconhecidas pelo público ou pela crítica, e convidam a "leituras desconexas" ou superficiais. Para ilustrar essa afirmação, no caso das antologias de poesia argentina, cabe mencionar que a compilação de poesia argentina de Jorge Santiago Pe-

\footnotetext{
${ }^{2} \mathrm{~A}$ tradução é minha. Esse será o caso sempre que a referência bibliográfica conste em outra língua. Agradeço a Walter C. Costa pela informação sobre esse artigo de Mujica.
}

(Ibidem: 14.)

" (MUJICA, Barbara. "Teaching literature: canon, controversy and the literary anthology". Hispania, v. 80, n. 2, maio 1997: 203.)

'(BAKHTIN, Mikhail. Estética da criação verbal. Tradução de Maria Ermantina Galvão G. Pereira. 3. ed. São Paulo: Martins Fontes, 2000: 279-281.) 
- (Buenos Aires: Editorial Calle Abajo, 1989.)

(Buenos Aires: Editora Aguilar, 1981.)

- "La recuperación de la poesía escrita durante los años de la dictadura militar en Argentina, agrupada según diferentes tendencias por Jorge Santiago Perednik en un libro ineludible para nuestro propósito [...]" (CROCE, M. "Poesia argentina año 2000". Cuadernos de "EI Matadero", 1. Serie Revistas Especializadas. Buenos Aires: Universidad de Buenos Aires, 1998: 15.)

(BENEDICT. Op. cit., 1996: 4.)

(Ibidem: 7.) rednik, Nueva Poesía Argentina durante la dictadura, 1976-1983,3* que, diferentemente da organizada, por exemplo, por Horacio Armani - intitulada Antología Esencial de Poesía Argentina (19001980), " foi uma seleção que não se apresentou como "essencial", nem foi publicada por uma grande editora, mas tem sido uma referência para múltiplos projetos posteriores relativos à atividade poética na Argentina das últimas duas décadas. Por exemplo, como lemos no estudo preliminar de Marcela Croce à antologia "Poesia argentina año 2000": "A recuperação da poesia escrita durante os anos da ditadura militar na Argentina, agrupada segundo diferentes tendências por Jorge Santiago Perednik em um livro ineludível para nosso propósito [...]". . Assim, concordamos com Benedict em que apesar de apresentarem especificidades nas formas, antologias e coletâneas não são fundamentalmente diferentes. As categorias de heterogeneidade ou contemporaneidade, utilizadas para caracterizar as "coletâneas" reforçando sua diferenciação das "antologias", são, de fato, categorias históricas. Textos considerados heterogêneos em um contexto podem deixar de sê-lo em outro. Na realidade, como diz a autora: "[...] antologias e miscelâneas constituem o mesmo gênero", porque partilham os mesmos meios de produção material, os processos de compilação e as formas que definem suas funções culturais.

\section{Antologia, "descontextualização" e discurso}

Um outro tópico que precisa ser tratado a partir de uma visão discursiva é a suposta descontextualização que seria inerente às antologias. Como as compilaçôes reeditam material proveniente de diversos contextos e de acordo com princípios e critérios diferentes, os textos incluídos se tornariam deshistoricizados, despolitizados e, portanto, "atemporais", imortais, ou "eternamente contemporâneos". Entretanto, entender a antologia como discurso requer analisar sempre as condiçôes específicas de sua produção. Não existe discurso descontextualizado. Se considerarmos a distinção de Pêcheux intradiscurso/interdiscurso, que se corresponde com a de formulação/enunciado em Foucault, ou seja, o nível da formulação produzida na horizontalidade da cadeia verbal e o nível de análise, interdependente, das memórias sócio-históricas

\footnotetext{
${ }^{3}$ Quando se tratar de antologias, constará a referência bibliográfica completa na primeira menção, juntamente com uma referência sintética, que será repetida em posteriores momentos da discussão.
} 
e/ou inconscientes implícitas na dimensão vertical do discurso, a observação sobre descontextualização pode ser aprofundada explicando regularidades enunciativas que levam a uma dada configuração discursiva da formulação de uma antologia, como veremos a seguir. Por exemplo, a antologia poética bilíngüe de múltiplos autores de Stanley Burnshaw, The Poem Itself, que analisei ao estudar a representação da poesia brasileira em antologias poéticas bilíngües continentais, editadas nas últimas duas décadas nos Estados Unidos, ${ }^{4}$ propõe-se a propiciar aos leitores de língua inglesa a experiência da leitura de poemas nas línguas francesa, alemã, espanhola, italiana e portuguesa. ${ }^{5}$ Assim, os poemas estão na língua de origem, sem traduçôes "oficiais" dos mesmos ${ }^{6}$ mas, na seqüência, são apresentados ensaios que "os discutem" em inglês, incluindo sempre transliterações em prosa dos poemas e comentários críticos. Não há notas biográficas dos autores, porém apresentações de sua vida e obra são freqüentes nesses ensaios, que não seguem um único "modelo" e são de autoria de numerosos colaboradores (relacionados em "Apêndice", com notas sobre procedência acadêmica e obras dos autores). Há também nesse Apêndice uma seção dedicada à prosódia, com considerações sobre métrica, rima e ritmo na poética e mais uma seção separada sobre teoria fonológica e fonética nessas línguas.

Com a finalidade de explicitar a descontextualização, faremos menção detalhada dos poetas da seção dedicada às línguas espanhola e portuguesa, tomando como eixo os autores brasileiros incluídos: Manuel Bandeira, Jorge de Lima e Cecília Meireles. O índice, no qual não constam especificações de origem nacional dos poetas, está organizado por ordem cronológica de nascimento de autor. Assim, Manuel Bandeira figura no sexto lugar da seção, após os poetas espanhóis Rosalía de Castro, Miguel de Unamuno, Antonio Machado, Juan Ramón Jiménez e León Felipe. Jorge de Lima, conforme o critério cronológico, ocupa o décimo lugar, após os autores já mencionados, mais o português Fernando Pessoa e os espanhóis Pedro Salinas e Jorge Guillén. Cecília Meireles está precedida pelo peruano César Vallejo e seguida pelos poetas espanhóis

\footnotetext{
${ }^{4}$ Desenvolvi esse projeto na Columbia University, em 2005, com apoio da Fapesp. ${ }^{5}$ Também há, no Apêndice, um único poema em russo, com transliteração ao inglês e ensaio em inglês, conforme o procedimento seguido na Antologia.

${ }^{6}$ Pois essa opção, segundo o antologista, ofereceria uma experiência de leitura de poesia "em inglês".
}

- (FOUCAULT, Michel. La arqueología del saber. México: Siglo XXI Editores, 1986: 144-145; PÊCHEUX, Michel. L'inquiétude du discours. Paris: Éd. des Cendres, 1990: 228-232.)

"(Fayetteville: The University of Arkansas Press, 1995.) 
- (SERRANI, Silvana. "Identidade e representação do Brasil em antologias poéticas bilíngües". In: MAGALHÃES, I.; GRIGOLETTO M.; CORACINI M. J. (orgs.). Práticas identitárias: Língua e discurso. São Carlos: Editora Claraluz, 2006: 103.)

- (Austin, TX: University of Texas Press, 1996.)
Federico García Lorca e Rafael Alberti, o espanhol-cubano Eugenio Florit e o chileno Pablo Neruda. Em poucas páginas, e sem qualquer informação ao leitor, percorrem-se décadas e continentes. Apenas um leitor que já conheça os autores, os países de origem, as obras e as épocas em que foram produzidas poderá situar-se em relação ao contexto dos textos compilados. A análise discursiva mostra que nesse tipo de proposta de antologia subjaz uma concepção de língua totalmente desvinculada da história; que a experiência de leitura se reduz aos sons da língua, em sua dimensão apenas física; e que para a compreensão é desconsiderada a materialidade sócio-histórica do sentido." Mas essa "descontextualização" não é inerente à definição do gênero. Existem muitas antologias cuja configuração discursiva favorece e, inclusive, reforça a contextualização por relaçôes que o gênero possibilita entre os textos compilados. E isso não acontece apenas em antologias dedicadas a um período específico, mas também em antologias "gerais" ou que abarcam grandes períodos históricos. Para ilustrar, referiremos à antologia, também territorialcontinental, de Stephen Tapscott, Twentieth-Century Latin American Poetry. Nesta antologia, todos os autores têm os países de procedência e datas de nascimento e morte detalhados no índice; além disso, um ensaio biográfico com consideraçōes sobre vida e obra de cada poeta antecede a apresentação dos poemas de cada autor. Também, a antologia conta com um prefácio, um longo estudo preliminar, um apêndice sobre concretismo brasileiro, bibliografias escolhidas de todos os poetas, índices de primeiros versos na língua de origem (espanhol ou português) e em inglês, e índice de autores e títulos. Nesse projeto antológico, são evidentes os esforços da proposta por contextualizar o material da antologia. Mas, conforme Bakhtin, os gêneros discursivos têm suas condições de produção e circulação que lhe são próprias nas diferentes esferas sociais. Uma antologia convida a leituras em que a configuração contextual é necessariamente diferente daquela dos textos originais, mas isso não significa que a descontextualização seja uma característica inerente ao gênero. Assim, constatamos que o olhar discursivo permite evitar generalizações simplificadoras em relação ao gênero antologia.

\section{Antologia e representação geopolítico-cultural}

Como se sabe, as tradições, os patrimônios literários nacionais e seus leitores foram constituídos, em boa parte, por antologias. A incidência do gênero, que a partir do século XIX refletiu explici- 
tamente as consolidações nacionais, hoje se observa na construção de blocos geopolíticos regionais.

Em seu estudo sobre a relação entre antologias e o processo de construção da União Européia, o tradutólogo Delabastita ${ }^{7}$ formula a hipótese de o bloco ser um "estado" em formação, cuja construção consciente e inconsciente de identidade "euronacional" é acompanhada significativamente pela literatura. ${ }^{*}$ Dentre as inúmeras antologias de literatura "européia", publicadas a partir do tratado de Maastricht, o autor escolhe duas de língua francesa para um estudo de caso que consiste em uma análise que põe em evidência posições e estratégias discursivas relevantes para a análise multicultural. Nos títulos das antologias consideradas, o número gramatical, assim como as metáforas mobilizadas, produz efeitos de sentidos muito diferentes. Mémoires parte do Renascimento, o período em que se tornou mais manifesta a divergência lingüística e cultural da Europa, ao passo que Patrimoine dedica quase a metade de seus quatorze volumes “às 'raízes' judaicas, cristãs, gregas, latinas, medievais e outras da literatura renascentista e pós-renascentista européia, redesenhando e ancorando modelos diacrônicos de continuidade a vários 'começos absolutos"'. Parecem atinadas as hipóteses desse autor quanto a essas antologias corresponderem a duas concepçōes da unidade regional: uma maximalista, que sustentaria a existência de uma essência européia que as antologias representariam, e uma minimalista que defenderia que o máximo possível é criar possibilidades de diálogo, complementaridade e enriquecimento mútuo, visando a construir a identidade européia plural. Nesta visão, sairão favorecidas as antologias multilíngües e, quando for preciso acrescentar tradução, a opção será por aquela que ponha em evidência a origem estrangeira intercultural, interlingual e intertemporal dos textos.

Em nosso contexto, não surpreende que concomitantemente ao crescimento dos acordos bilaterais entre os dois países membros principais do Mercosul haja sido concretizado o projeto de uma antologia binacional como a Antologia Bilíngüe Puentes/Pontes: Poesia Argentina e Brasileira Contemporânea. A compilação inclui poemas de quarenta autores contemporâneos - vinte brasileiros e vinte argentinos -, nascidos entre os anos 1920 e $1950 .{ }^{8}$ Nes-

\footnotetext{
${ }^{7}$ Agradeço a Walter C. Costa o envio da versão ainda inédita do texto de Dirk Delabastita.

${ }^{8}$ A relação dos poetas será detalhada na próxima seção do artigo.
}

"(DELABASTITA, Dirk. "Anthologies, Translations and European Identities". In: DELABASTITA, Dirk; FRANSSEN, Paul; DE VOS, Jozef. Shakespeare and European politics. Newark: University of Delaware Press, 2008.)

'(BIET, Christian; BRIGHELLI Jean-Paul (ed.). Mémoires d'Europe: Anthologie des littératures européennes. Paris: Gallimard, 1993, 3 v.; e POLET, Jean-Claude (ed.). Patrimoine littéraire européen. Bruxelas: De Boeck Université, 1992-2000, 15 v. Doravante, Mémoires e Patrimoine, respectivamente.)

"(DELABASTITA. Op. cit.)

* (BUARQUE DE HOLLANDA, Heloisa; MONTELEO$N E$, Jorge. Buenos Aires: Fondo de Cultura Económica, 2003. Doravante Puentes/Pontes.) 
(BUARQUE DE HOLLANDA. In: Puentes/Pontes: 280.) sa antologia, tanto os ensaios introdutórios de cada parte como todos os poemas encontram-se em português e espanhol, em páginas contíguas. $\mathrm{O}$ discurso antológico em Puentes/Pontes parece estar constituído por duas produções paralelas. De fato, parece que estamos frente a duas antologias justapostas. Os critérios de organização de cada parte não estão articulados à outra. No discurso da compilação brasileira, as ressonâncias discursivas em torno do devir histórico estão mais presentes do que no discurso da compilação argentina. $\mathrm{O}$ foco de Buarque de Hollanda não é meramente cronológico, mas em sua cartografia transparece a preocupação de situar o leitor - principalmente o não brasileiro - em relação ao contexto sócio-histórico. Assim, não são raras as ressonâncias discursivas em torno de palavras como momento, periodo, faixa de tempo, etc. Por exemplo:

[...] o momentum deste conjunto de poetas foi marcado por um período convulsivo de transformações políticas e econômicas no país. Uma faixa de tempo que cobre desde o período áureo de modernização e desenvolvimento do governo de Juscelino Kubitschek, com a intensificação do processo de industrialização e de novas relaçôes com o capitalismo monopolista internacional, até a emergência dos movimentos revolucionários populares e estudantis que culminaram com os anos de chumbo subseqüentes aos golpes militares de 1964 e 1968, quando a forte vigência da censura e da repressão policial polariza a produção cultural de resistência ao regime de exceção.

Na parte dedicada à poesia argentina, entretanto, o critério do devir histórico aparece representado pela negativa, como mostraremos detalhadamente na próxima seção. $\mathrm{O}$ projeto antológico Puentes/Pontes representa uma contribuição valiosa para a memória da cultura poética do Cone Sul Latino-Americano e, especialmente, do Brasil e da Argentina. É inovador porque convoca organizadores reconhecidos pela trajetória nos estudos literários, para uma proposta em que a atenção ao bilingüismo recobre todas as seções do projeto. Essa postura está associada à participação de tradutores competentes e vinculados muito diretamente à produção poética. De todas as formas, o exame de ressonâncias discursivas nas fontes secundárias - tanto nas recorrências de formulações explícitas (intradiscurso) quanto nas memórias (do interdiscurso) mobilizadas ao construir a antologia - leva a hipotetizar que a "barra" que separa as duas palavras do título nas páginas de rosto funcione, talvez, como uma metonímia dos obstáculos para uma maior concretização da "ponte" cultural anunciada. 
Para finalizar este tópico sobre a representação nacional ou regional, impõe-se fazer considerações sobre as antologias didáticas. Elas, que produzem um grande impacto na transmissão e definição da literatura, são objeto de críticas constantes, sob a acusação de serem instrumentos de deformação intelectual dos alunos. Os argumentos mais recorrentes contra as antologias didáticas são, como sintetiza Fraisse, por um lado, a miopia intelectual e estética dos autores - sobretudo em relação à produção mais recente -, por outro, tanto a estreiteza ideológica dos compiladores quanto os dispositivos de coerção ou censura do discurso editorial.

Com todos os seus defeitos, em muitos casos inegáveis, as antologias didáticas se revestem de uma importância singular para os estudos de memória sociocultural. No Brasil, o caso da Antologia Nacional ilustra paradigmaticamente a questão. O tema foi objeto de teses realizadas por Márcia Razzini, que observa:

[...] a adoção compulsória (até 1930) e as sucessivas reedições (a última, a $43^{a}$ edição, é de 1969) indicam que a Antologia Nacional foi um livro de leitura "intensiva” de várias gerações de brasileiros que passaram pela escola secundária. (...) Os autores e excertos (brasileiros e portugueses) selecionados na Antologia Nacional eram apresentados de forma moderna, divididos por períodos históricos (e não mais por gêneros), dispostos na ordem cronológica inversa, "do $19^{\circ}$ ao $16^{\circ}$ Século", privilegiando os brasileiros contemporâneos (já separados dos portugueses), por onde o estudo do vernáculo começava. ${ }^{{ }^{*}}$

Em um trabalho anterior, ${ }^{10^{*}}$ a autora observou a função formadora dessa obra em grandes autores brasileiros, como Manuel Bandeira e Pedro Nava. Este último diz:

Cedo descobri minha distração. Logo fiquei fiel a quatro amigos que me valiam na hora em que eu não tinha vontade de estudar. Sonhava com eles. Me acompanharam o curso todo. Foram Os Lusiadas, o Théatre classique de Régnier, a Antologia Nacional de Fausto Barreto e Carlos de Laet e o irreal, o inimaginável Atlas de Crosselin-Delamarche.

E em Itinerário de Pasárgada Manuel Bandeira afirma: "Do Camóes lírico apenas sabia o que vinha nas antologias escolares,
- (FRAISSE, Emmanuel. Les anthologies en France. Paris: PUF, 1997: 234.)

' (RAZZINI, Márcia. O EspeIho da Nação: a Antologia Nacional e o ensino de português e de literatura (18381971). 2000. Tese de Doutorado - IEL-UNICAMP.)

"(RAZZINI, Márcia. Antologia Nacional (1895-1969): Museu literário ou doutrina?. 1992. Dissertação de Mestrado - IEL-UNICAMP.)

(NAVA, Pedro. Balão cativo: Memórias 2. 4. ed. Rio de Janeiro: Nova Fronteira, 1986: 334 e 335, apud. RAZZINI. Op. cit., 1992: 43 e 45.$)$

\footnotetext{
${ }^{9}$ Tese de doutorado defendida com orientação de Marisa Lajolo no IEL-UNICAMP. Disponível (30/06/08) em: http://ead.mackenzie.com.br/mackvirtual/ $\mathrm{mod} /$ resource/view.php?id=1311.

${ }^{10}$ Dissertação de Mestrado, defendida com orientação de Marisa Lajolo no IELUNICAMP. Texto arquivado na Biblioteca do IEL.
} 
(BANDEIRA, Manuel, Itinerário de Pasárgada. In: Obras completas, 4. ed. Rio de Janeiro: Nova Aguilar, 1977: 35-36, apud. RAZZINI. Op. cit., 1992: 46.$)$

(FRAISSE. Op. cit.: 253.)

(FRAISSE, Op. cit: 254255.)

(BENEDICT. Op. cit.: 9-10)

·(Ibidem: 220.)

- (PROSDOCIMI, María del Carmen. Las antologias poéticas argentinas (19601970): Guías bibliográficas 10. Buenos Aires: Publicação do Instituto de Literatura Argentina Ricardo Rojas, 1971: 5.) especialmente na que era adotada no Ginásio [que era a Antologia Nacional de Barreto e de Laet]".

A antologia didática - atacada como conformista, tradicionalista, normativa, ou mesmo, incompetente - não é, portanto, um artefato cultural isolado. Como observa Fraisse, para a inclusão de novos autores ou obras, é preciso que o antologista se apóie num discurso de inclusão vinculado à crítica e ao discurso universitário, por sua vez, relacionado à evolução do estatuto social e simbólico dos professores de Letras na universidade. ${ }^{*}$ Talvez, valha a pena lembrar também que se espera que o uso de antologias seja associado à alternância com a leitura de outras obras e de textos completos, muitos deles com edições dotadas de aparelhos críticos escolares. ${ }^{*}$ Assim, concluímos com esse autor que a antologia didática, como toda antologia, pode propiciar encontros significativos de seu leitor com a literatura.

Antologia, crítica, memória discursiva e capital simbólico

Os tópicos tratados na primeira parte introduzem a questão, a nosso ver, de maior importância nos estudos sobre antologia: o gênero representa um dos veículos pelos quais a crítica literária se torna uma arena de auto-exame cultural. Como observa Benedict: "essa cultura [...], enquanto construída pela antologia literária mediante sua retórica, suas práticas de compilação e circulação, bem como seu papel cultural, constitui a internalização de valores de crítica." Ao facilitar a categorização da literatura, as compilações revelam princípios organizacionais que indicam formas em que se espera que os leitores comprem, leiam e pensem sobre a escrita literária. Ou, nas palavras ousadas de María del Carmen Prosdocimi, bibliógrafa de antologias poéticas na Argentina: "a antologia é um ensaio crítico levado à prática.” Essa dimensão crítica da antologia é também aprofundada por Walter C. Costa em seu estudo sobre a Antologia de la literatura fantástica de Jorge Luis Borges, Adolfo Bioy Casares e Silvina Ocampo. Como diz o autor, essa antologia que foi reeditada repetidas vezes e permanece em catálogo sessenta e sete anos após sua aparição - inovou profundamente pois:

se tomavam liberdades em relação ao cânone internacional e nacional e propunha implicitamente uma nova poética [...]. O resultado é um livro compósito, cuja estética nasce da justaposição de textos díspares. O elemento comum é uma certa recusa ao realismo, en- 
tão predominante na ficção argentina e hispano-americana, e um apelo à imaginação e ao fantástico, dois dos aspectos que caracterizarão a literatura dos três antologistas, mas também caracterizarão a literatura rioplatense e hispano-americana."

A projeção dessa antologia, como nos informa Costa, excede o âmbito hispânico; isso é atestado pelo fato surpreendente de uma antologia que surgiu da tradução ao espanhol de muitas obras de origem anglo-saxônica ter sido, por sua vez, traduzida para o inglês.*

Com a finalidade de examinar, no caso de antologias poéticas argentinas, o funcionamento do gênero, fizemos inicialmente um levantamento de quarenta antologias de poesia argentina das últimas três décadas, ${ }^{11}$ e elaboramos a seguinte taxonomia:

\section{Antologias bilíngües}

Exemplos: Espanhol/Francês: SALAS, H. (org.). Poésie argentine du XXe siècle. Genebra: Editions Patiño, 1996 (doravante Poésie). Espanhol/Inglês: GRAHAM-YOOLL, A.; SAIMOLOVICH, D. Twenty poets from Argentina. Londres: Redbeck Press, 2004 (doravante Twenty poets). Espanhol/Português: JOSEF, B. (seleção, prefácio e tradução). Poesia argentina 1940-1960. São Paulo: Iluminuras, 1990. BUARQUE DE HOLLANDA, H.; MONTELEONE, J. Puentes/Pontes, Op. cit.

\section{Antologias nacionais gerais}

Exemplo: ARMANI, H. (org.). Antología esencial de poesía argentina (1900-1980). Buenos Aires: Aguilar, 1981.

\section{Antologias temáticas}

Exemplo: RODRÍGUEZ MUJICA, D. La erótica argentina: Antología poética 1600/1990. Buenos Aires: Catálogos/El Caldero, 1994.

\section{Antologias de grupos humanos específicos}

Exemplo: GRUSS, I. (org.). Poetas argentinas (1940-1960). Buenos Aires: Ediciones del Dock, 2006.

\footnotetext{
${ }^{11}$ A relação completa das antologias consultadas consta no site do Projeto de Pesquisa Antologias, Discurso e Práticas Letradas: www.antologiasediscurso.iel. unicamp.br.
}

" (COSTA, Walter C. "Antologia e circulação de gêneros: a Antologia de la literatura fantástica de Silvina Ocampo, Jorge Luis Borges e Adolfo Bioy Casares". Conferência proferida no IEL-UNICAMP em 19 de setembro de 2007.)

"(BORGES, Jorge Luis; BIOY CASARES, Adolfo; SILVINA Ocampo (ed.). The book of fantasy. Londres: Black Swan, 1990.) 


\section{Antologias de correntes estético-poéticas}

Exemplo: SOLA, Graciela de. Proyecciones del surrealismo en la literatura argentina. Buenos Aires: Ed. Culturales Argentinas, 1967.

\section{Antologias regionais, provinciais e de cidades ou bairros}

Exemplos: BURTON, G. Poesía patagónica. Neuquén: Fundación Banco Provincia del Neuquén / Subsecretaría de Educación y Cultura de Neuquén, 1991. D’ANNA, E. La única ciudad. Antología de la poesía de Rosario. Rosario: Homo Sapiens, 1994.

\section{Antologias para públicos específicos}

Exemplo de antologia paradidática para jovens: MUSCHIETTI, D. Poesia argentina del siglo XX. Buenos Aires: Ediciones Colihue, 1998. 5a reimpressão.

\section{Antologias sobre formas poéticas ou variedades lingüísticas específicas}

Exemplos: SALAS, H. Clásicos de la poesía lunfarda: Antología. Buenos Aires: Ameghino, 1999.

\section{Antologias vinculadas a revistas ou grupos específicos}

LOMBARDÍA, G. Antología Último Reino. Buenos Aires: Libros de Tierra Firme, 1987.

Em um segundo momento, com a finalidade de enfocar questôes de memória transnacional nas antologias, realizamos um estudo de caso que consistiu no exame de ressonâncias discursivas nas três mais recentes antologias bilíngües (espanhol/francês; espanhol/inglês e espanhol/português) de poesia argentina. A principal categoria metodológica com que operamos na análise foi a de ressonância discursiva, isto é, a recorrência de palavras (que sejam, ou não, de uma mesma família lexical), construções (que sejam, ou não, paráfrases sintáticas) ou modos de dizer que se repetem em um discurso

- (SERRANI, Silvana. A Linguagem na pesquisa sociocultural. Um estudo da Repetição na Discursividade. 2. ed. Campinas: Editora da Unicamp, 1997.) e constroem, dessa forma, representaçôes de sentidos predominantes." Observamos ressonâncias discursivas em torno dos referentes: poesia, poetas e antologia em prefácios, ensaios preliminares, prólogos, notas biográficas de autores e/ou tradutores, ou posfácios. 
Hoje em dia, apesar de um contexto pouco estimulante, apesar das dificuldades de edição e do pouco entusiasmo dos leitores pela poesia - fenômeno constatado em escala mundial -, os últimos números dão um milhar de títulos por ano, o que traduz mesmo assim a vitalidade da poesia argentina."

Na seção de poesia argentina na antologia bilíngüe espanhol/ português Puentes/Pontes, ressoam sentidos vinculados à negação da representação histórica da poesia na antologia:

Nesta antologia a percepção da poesia argentina não é a de uma tradição sucessiva no tempo, que se desenvolve desde o passado até o presente, nem a de uma herança transmitida, na qual cada poeta tem um lugar fixo e definitivo. Seu proceder é inverso: reconhece a partir do presente uma trama possivel, mas não exclusiva; multiplica origens inconclusas, estrutura-se de modo descontínuo; compóe uma figura constelada na qual todos os poetas operam de um modo simultâneo... (...) os vinte poetas escolhidos conformam uma trama de leituras que remete mais à sua atualidade do que à sua genealogia.

Em Twenty poets se representa a poesia dos anos noventa vinculada ao que Samoilovich chama de visibilidade:

A visibilidade é, no meu entender, uma conquista em uma poesia que, como a argentina, em algum momento - a partir de uma leitura filistéia do barroco, ou pior, da teoria literária - esteve à beira da tentação de condenar tudo o que não estivesse velado, ou não fosse auto-referente, confuso, ambíguo, tremente na sintaxe e abstrato [...] É isto o que eu chamo visibilidade, o núcleo visivel ou argumental em torno do qual o poema se articula, em torno do qual se pode sonhar.

Seria interessante pôr em evidência ressonâncias discursivas que constroem efeitos de crítica, em relação a temas específicos, nas antologias bilíngües apontadas e também em uma monolíngüe. Embora com notáveis diferenças materializadas pela inclusão de outros sentidos (ver grifos de ressonâncias em itálico), parece haver alguma ressonância parcial da representação em Poésie no estudo preliminar da antologia de Croce:

indagar como funciona a poesia na história, quem escreve poesia, como circulam os poemas em uma sociedade onde o utilitarismo é a credencial indispensável para justificar a própria existência [...]. Nesta década final do século [...] Qual é o lugar da poesia frente a esse panorama? [...] A poesia é, como toda a literatura, um exílio voluntá-
*Aujourd'hui, malgré un environnement peu stimulant, en dépit des difficultés de l'édition et du peu d'engouement des lecteurs pour la poésie - un phenomène constaté à l'echelle mondiale-, les derniers chiffres donnent un millier de titres par an, ce qui traduit tout de même la vitalité de la poésie argentine. (SALAS, Poésie: 19.)

+ (MONTEleONE. Puentes/ Pontes: 22.)

"Visibility is, in my own understanding, a victory in poetry which, as in Argentina at some time, seemed to condemn anything that was not disguised - in a philistine reading of the baroque, or worse, of literary theory - preferring poetry to be self-indulgent, confused, ambiguous, stammering in syntax, and abstract in its development. [...] This is what I call visibility, the visible or script body around which the poem is built, from which a dream is possible. (SAIMOLOVICH, D. Twenty Poets: 12.) 
* indagar cómo funciona la poesía en la historia, quiénes escriben poesía, cómo circulan los poemas en una sociedad donde el utilitarismo es la credencial indispensable para justificar la propia existencia $[. .$.$] . En esta déca-$ da final de la centuria [...] Cuál es el lugar de la poesía frente a ese panorama? [...] La poesía es, como toda la literatura, un exilio voluntario [...] retiro de un lugar que se ha vuelto intolerable. Pero también es - como ya lo sabía Lugones [...] el espacio del centinela, el palco del arengador, la tarima del profesor y el escenario del ateneo anarquista. (CROCE, M. Op. cit.: 7-9.)

(SIEBENMANN, Gustav. Poesía y poéticas del siglo $X X$ en la América Hispana $y$ el Brasil. Madrid: Gredos, 1997: 461-463.)

(Ibidem: 465-468.) rio [...] retiro de um lugar que se tornou intolerável. Mas também é - como já sabia Lugones [...] o espaço do sentinela, o palco do líder, o espaço do professor e o cenário da associação anarquista.

Ressonâncias discursivas em torno dos poetas

De modo introdutório ao assunto da representação de poetas argentinos em antologias, cabe referir os resultados nesse campo do estudo do hispanista alemão Gustav Siebenmann, que, dentre outras análises, fez um levantamento quantitativo de autores em antologias de poesia hispano/ibero-americanas. O corpus de Siebenmann é formado por cinqüenta e sete antologias hispânicas em alemão, espanhol, português, francês e italiano* e, em relação à poesia argentina o resultado desse levantamento de número de poemas e autores foi: Jorge Luis Borges: 129 poemas; Leopoldo Lugones: 46 poemas; Oliverio Girondo: 40 poemas; Ricardo E. Molinari: 40 poemas; Alfonsina Storni: 39 poemas; Alejandra Pizarnik: 36 poemas; Roberto Juarroz: 27 poemas; Enrique Molina: 27 poemas; Francisco Luis Bernárdez: 26 poemas; Alberto Girri: 25 poemas; Leopoldo Marechal: 25 poemas; Juan Gelman: 22 poemas e Baldomero Fernández Moreno: 20 poemas.

Em nosso estudo de caso comparativo de antologias bilíngües de poesia argentina, constatamos as seguintes ressonâncias discursivas:

Em Poésie, são configuradas as seguintes representações para a organização dos poetas na antologia que cobre a poesia de todo o século XX:

Os precursores; a geração martinfierrista; a nova onda - os jovens dos anos trinta; novo romantismo e vanguarda - a geração dos anos quarenta; quinze anos fecundos - 1944-1959; em face da realidade - a geração dos anos sessenta; os anos de fogo - a partir dos anos setenta. Os últimos dois agrupamentos incluem os seguintes poetas: Humberto Costantini, Leonidas Lamborghini, Juan Gelman, Saúl Yurkievich, Miguel Angel Bustos, Juan Octavio Prenz, Gianni Siccardi, Horacio Salas, Luisa Futoransky, Edgardo Gili, Alberto Szpumberg, Daniel Salzano, Fernando Sánchez Sorondo, Rafael Felipe Oteriño, Santiago Sylvester, Santiago Kovadloff, Manuel Ruano, Daniel Freidemberg, Arturo Carrera, Jorge Ricardo Aulicino e Jorge Boccanera. 
Em Puentes/Pontes, a representação dos poetas argentinos está configurada em torno das seguintes ressonâncias:

- "A poesia de sujeito lírico, biografia e memória", representada por César Fernández Moreno; Juana Bignozzi e Juan Gelman - "A voz do duplo": Alejandra Pizarnik e Susana Thénon

- "Poema e espaço sagrado": Amelia Biagioni, Olga Orozco, Héctor Viel Témperley e Francisco Madariaga

- “Fabulaçôes da persona”: Leónidas Lamborghini, Néstor Perlongher, Aldo Oliva e María del Carmen Colombo

- "Percepçôes do objeto": Edgar Bayley, Alberto Girri, Roberto Juarroz e Joaquín O Gianuzzi

- "Contemplação e poema": Hugo Padeletti; Arturo Carrera e Diana Bellessi."

Em Twenty poets, o segundo organizador e tradutor, Andrew Graham Yooll, diz: "Quando a seleção começou, foi decidido que aqueles a ser traduzidos teriam quarenta anos ou menos."*

A seleção de poetas é a seguinte: Fabián Casas, Walter Cassara, Carolina Cazes, Washington Cucurto, Edgardo Dobry, Verónica Viola Fishcer, Rodrigo Eduardo Galarza, Martín Gambarotta, Danniel García Helder, Silvio Mattoni, Roxana Paez, Martín Prieto, Sergio Raimondi, Patricia Rodón, Alejandro Rubio, Guillermo Saavedra, Gabriela Saccone, Carlos Schilling, Beatriz Vignoli e Laura Wittner.

Em relação à auto-representação de antologia, nas três coleções - Poésie, Puentes/Ponts e Twenty Poets - ressoam sentidos de incompletude necessária, seja pela metáfora da ponta do iceberg, de trama no tapete (à la Henry James) ou ainda sem metáfora, pela explicitação pragmática de restrições orçamentárias para a realização do empreendimento antológico:

Esta antologia [...] é apenas a parte que emerge do iceberg, a abordagem de um universo cujo conhecimento completo não se poderia encontrar em uma antologia, mas nas bibliotecas.

Esta é uma das figuras possiveis da tapeçaria. É incompleta, é fervoro$s a$, é parcial. Omite as horas, as longas horas de escritura e o tempo da vida e o que se esqueceu em cada um dos atos dos poetas. Mas sabe que ainda está aí, grandiosa em sua leveza, aquela parte da Argentina que não se perdeu, sua preciosa intimidade na memória da linguagem.
(MONTELEONE. Puentes/ Pontes: 22-32.)

" "When the selection was started, it was decided that those to be translated would be aged forty or under."

'Cette anthologie [...] n'est jamais que la partie émergée de l'iceberg, l'approche d'un univers dont la connaissance parfaite $[. .$.$] ne saurait se$ trouver dans une anthologie, mais dans les bibliothèques. (SALAS. Poésie: 19-20.

- (MONTELEONE. Puentes/ Pontes: 34 .) 
"Apart from the arbitrary setting of an age limit, the poets to be included had to have at least one book published, and (...) had to be living in Argentina. (...) Another aim, from the start, was to try to break out of Buenos Aires, and find good poets in the provinces (...). We have left out some good and promising poets in such a brief selection. This is inevitable when limits are set by printing costs and available funding (...) In the end, the reader will have to decide whether or not the choice is a good one and, if from it, a small window is opened on new writing in Argentina. (GRAHAM-YOOLL. Twenty poets: 8 )
"(GASPARINI, Pablo. "Patria y filiatrías (exilio y transnacionalidad em Gombrowicz, Copi y Perlongher)". Hispamerica, v.105, dez. 2006, ano XXXV: 45.)

- (STEINER, George. Extrateritorial: a literatura e a revolução da linguagem. São Paulo: Companhia das Letras, 1990: 15-31.)

- (CASANOVA, Pascale. A República mundial das letras. São Paulo: Estação Liberdade: 55 .)
Além do recorte arbitrário de uma idade limite, os poetas que seriam incluídos na antologia teriam de ter pelo menos um livro publicado e [...] estar morando na Argentina. [...] Um outro objetivo, desde o começo, foi procurar quebrar o predomínio portenho e encontrar bons poetas nas provincias [...]. Tivemos que deixar fora alguns bons e promissores poetas nesta breve seleção. Isso é inevitável quando os limites são estabelecidos pelos custos de edição e pelos recursos disponiveis [...] No final, o leitor terá de decidir se a seleção é boa e se a partir dela uma pequena janela se abre em relação à nova escrita em Argentina.*

Finalmente, cabe apontar que constatamos com freqüência nas fontes secundárias de nosso corpus de antologias ressonâncias discursivas que produzem recorrentemente sentidos contraditórios entre o pletórico e o lacunar. Sabe-se que o espaço da antologia é lacunar, mas parece ser preciso que o antologista se desculpe pela antologia não ser pletórica. Essa é mais uma materialização de contradiçóes que habitam o discurso das antologias.

\section{Considerações Finais}

Faz bem Gasparini* quando relaciona, contraditoriamente, a tese de Steiner, sobre a necessidade de uma intempérie nacional, intrínseca ao autor moderno, e a noção de transnacionalidade de Casanova, que permite pensar que "as literaturas não são a emanação de uma identidade nacional, elas são construídas na rivalidade (sempre negada) e na luta literária, sempre internacionais". Da perspectiva da análise do discurso, se pensarmos nas condiçóes de produção dos textos, cabe lembrar que o ensaio de Steiner foi produzido no ápice das teorias chomskianas de estruturas lógicosemânticas universais e falantes nativos ideais. Talvez essa interdiscursividade explique o fato de Steiner se referir, metaforicamente, a escritores como Wilde, Beckett, Borges, Pound e Nabokov como "esperantistas". De todas as formas, embora seja importante a apontada dessacralização da teoria de Steiner, o avanço teórico de dar estatuto constitutivo ao extraterritorial ainda é relevante ao estudar os processos contraditórios da produção e leitura de escrita em antologias, sobretudo nas bilíngües. Mas, é no quadro do enfoque da produção e disputa de capitais simbólicos literárioculturais, salientado pela discípula de Bourdieu, que entendemos uma das funções da produção e análise de antologias e, especialmente, das bilíngües. 
Assim, concluímos este texto com uma pergunta: será muito ingênuo levantar a hipótese de trabalho de que a antologia pode cumprir um papel singular, transgressor e renovador a) como discurso especialmente polêmico, que pode entrar em fácil relação com o fragmentarismo de outros discursos sociais dominantes; ou b) como contra-discurso na disputa com patrimônios culturais hegemônicos da atualidade? 


\section{Silvana Mabel Serrani}

Professora titular e coordenadora do CEHISP-Centro de Esutudos Hispânicos no IEL-Unicamp. Formada em Letras pela Univ. de Buenos Aires, Mestre e Doutora em Lingüística - Análise do Discurso pela Unicamp. Pós-doutorado no Dept. of Transcultural Studies da Columbia University. Pesquisadora do CNPq desde 1992. Publicaçôes, entre outras revistas em Cahiers du français contemporain; Signo y Seña, RASAL; DELTA, etc. A Linguagem na Pesquisa Sociocultural.Campinas: Ed. Unicamp, 2a ed.1997, etc. Teses orient.: 16 def.; 6 em andamento.

Palavras-chave: antologia; estudos hispânicos; análise do discurso; poesia argentina.

\section{Resumo}

Este artigo discute, a partir da perspectiva da Análise do Discurso, propriedades gerais da antologia, enquanto gênero paradigmático da escrita compilada. Distinçôes (como coletânea/antologia) e características gerais atribuídas ao gênero (por exemplo, a descontextualização de textos) são problematizadas, discutindo-se, também, efeitos discursivos da representação geopolítico-cultural em antologias de múltiplos autores e didáticas. A tese principal é que conceber as antologias como discurso permite avançar na compreensão da materialidade e do funcionamento do gênero. As ilustrações decorrem, principalmente, do âmbito dos Estudos Hispânicos, mas faz-se referência, também, a outros contextos. Propóe-se a análise discursiva comparativa como via para aprofundar a compreensão do funcionamento da antologia enquanto lugar de memória, veículo de crítica e capital simbólico. Apresentam-se resultados de um estudo de caso sobre antologias bilíngües de poesia argentina, no qual se examinam ressonâncias discursivas de fontes secundárias - prólogos, posfácios, etc. Nas conclusões, é salientada a relevância das antologias bilíngües em relação à noção de transnacionalidade cultural. 


\section{Abstract}

This article discusses, from a Discourse Analysis perspective, general properties of anthologies, as paradigmatic realizations of compiled writing. Formal distinctions (such as miscellany/anthology) and general characteristics attributed to the genre (for instance, the decontextualization of contents) are questioned and discursive effects of geopolitical-cultural representations in anthologies are also examined. The main claim is that conceiving anthologies as discourse allows us to go further in the comprehension of the genre's materiality and functioning. Illustrations are mainly drawn from anthologies belonging to Hispanic Studies, but references to other contexts are also made. The proposal of a discursive comparative analysis is presented, searching to deepen the comprehension of the anthology's functions as a memory and cultural legacy, an instrument of criticism and a symbolic capital. Results from a case study on bilingual anthologies of Argentinian poetry are presented. To conclude, the relevance of the anthology regarding the notion of cultural trans-nationality is underlined.

\section{Resumen}

Este artículo discute, a partir de la perspectiva del Análisis del Discurso, propiedades generales de la antología, en tanto género paradigmático de la escritura recopilada. Distinciones (tales como antología/recopilación) y características generales atribuidas al género (por ejemplo, la descontextualización de los textos) son problematizadas, discutiéndose también los efectos discursivos de la representación geopolítico-cultural en antologías de múltiples autores y didácticas. La tesis principal es que concebir las antologías en tanto discurso permite avanzar en la comprensión de la materialidad y funcionamiento del género. Las ilustraciones corresponden principalmente al ámbito de los Estudios Hispánicos, pero se hace referencia también a otros contextos. Se propone el análisis discursivo como un camino para la comprensión del funcionamiento de la antología en tanto lugar de memoria, vehículo de crítica y capital simbólico. Se presentan resultados de un estudio de caso sobre antologías bilingües de poesía argentina en el cual se examinan resonancias discursivas de fuentes secundarias - prólogos, postfacios, etc. En las conclusiones se destaca la relevancia de las antologías bilingües en relación con la noción de transnacionalidad cultural.
Key words: anthology; Hispanic studies; discourse analysis; Argentinian poetry.

Palabras Ilave: antología; estudios hispánicos; análisis del discurso; poesía argentina.
Recebido em 28/03/2008

Aprovado em $30 / 06 / 2008$ 